\title{
EdTech Culturation: Integrating A Culturally Relevant Pedagogy into Educational Technology
}

\author{
Jenny Eppard, Amir Kaviani, Michael Bowles and Jason Johnson \\ Zayed University, United Arab Emirate \\ jrk3r@virginia.edu \\ amir.kaviani@zu.ac.ae \\ michael.bowles@zu.ac.ae \\ jason.johnson@zu.ac.ae
}

\begin{abstract}
In recent years, the use of technology in educational contexts including e-learning has become increasing ubiquitous. While it is commonly believed that technology use can facilitate the process of teaching and learning, it is of paramount importance to adopt a Culturally Relevant Pedagogy (CRP) to address the needs of students who might experience difficulty because of cultural, linguistic and technological obstacles that might be inherent in the use of educational technology. With this consideration in mind, the present paper reports on the findings of a qualitative research involving three case studies based on structured interviews with three university professors who are experts in developing digital tools and applications for educational purposes. The participants recorded their responses to interview questions on Google Docs over a period of one month, and the data was analysed for significant themes. The data revealed that all participants believe that cultural, methodological and pedagogical barriers can significantly affect the use of educational technology in face-to-face and online classes and can consequently impact student learning. The emergent themes in the data indicate that a solid understanding of the local context in which the process of teaching and learning takes place, flexibility in terms of one's methodological approaches to teaching and embracing differences in students' knowledge and abilities can help ensure students succeed in their academic endeavours, they are uncritically accepted and treated in an equitable manner regardless of their competency level. All three participants in the study believe that while there are some cultural and linguistic barriers in e-learning contexts and in developing and using technological applications for students, through adopting the core principles of a culturally relevant pedagogy (CRP), they have been successful in achieving the course learning outcomes for their students. They argue that by adapting the language used in applications to the linguistic level of students, using familiar and culturally relevant themes, and adopting a blended approach in which technology complements face-to-face instruction, a better dialogue is established between the teacher and the students, and learning is thus facilitated. The findings of this study reveal that becoming familiar with the local culture, the relevant prescriptions and proscriptions can furnish the education technology developers with the requisite knowledge for creating applications that are relevant to students' lives and are thus more effectual. Similarly, the results show that educational applications should provide a suitable platform to create and maintain an ongoing intrapersonal and interpersonal dialogue for the students to help them engage in the process of learning in a regular and consistent manner. Implications for pedagogy and research will be discussed.
\end{abstract}

Keywords: Culturally Responsive Pedagogy, Educational Technology, EdTech Culturation, Equitableness, Inclusiveness

\section{Introduction}

The United Arab Emirates has a large expatriate population (88.52\%) and a relatively small local citizenry (11.5\%) (Population of the UAE, 2020). With such a large and diverse expatriate population, providing a space for Emiratis to engage in cultural practices specific to the local context is becoming increasingly difficult. The public education sector in the UAE tries to provide space and resources for students to feel culturally connected. For example, public universities enrol mostly local students. However, while the students are Emirati, most of the teaching faculty come from outside the country (Qs Top Universities, 2020). Many of the resources such as textbooks and educational technology are imported mainly from English-speaking countries. In such a context which resembles other educational settings that comprise a mostly western pedagogical framework with local students (Ladson Billings, 1995), there is a need to include elements of Emirati society in teaching and learning, such as content and learning strategies, in order to empower the local student population.

Like other parts of the world, the UAE is moving from an educational environment of traditional, rote learning to one that highlights the importance of 21st Century Skills such as critical thinking, creativity, collaboration and communication skills (UAE Ministry of Education: Quality Education, December 2020). In line with this, educational technology is central to integrating these aspects of learning and teaching practice (Bond et al., 2020). However, ISSN 1479-4403 516

CACPIL

Reference this paper: Eppard, J., et al., 2021. EdTech Culturation: Integrating A Culturally Relevant Pedagogy into Educational Technology. The Electronic Journal of e-Learning, 19(6), pp. 516-530, available online at www.ejel.org 
similar to the use of other resources, the challenge is to implement digital technologies that empower the local students, and that these technologies are not getting in the way of learning (O'Donnell, and Sharp, 2012; Kennedy and Dunn, 2018).

In this research paper, the researchers would like to recommend the term "EdTech culturation" as a pedagogical approach which requires a sound understanding of and adeptness in the use of technology in classroom and outof-class teaching and learning, which is appropriate for the relevant sociocultural context. The present research thus focuses on EdTech culturation as a dynamic process as well as a valid ethnomethodological approach in the context of higher education. Such an approach represents a Culturally Responsive Pedagogy (CRP) in diverse sociocultural contexts and facilitates achieving learning outcomes. In light of this perspective, the researchers believe through the use of appropriate technology, digital educational tools will be more meaningful and relevant to the specific needs of the students and help to engage in learning in a consistent and effective manner.

In the present study, the researchers have endeavoured to use technological tools and teaching approaches that are culturally appropriate and relevant to the context. While almost all the students the faculty teach come from a homogenous background culturally and linguistically, the use of "imported" technology in such a context can sometimes lead to problems for students, as they might not be able to understand how to use digital tools effectively in accordance with the expectations of the faculty who often come from other cultures. Such problems for students from Arab countries have been highlighted by some researchers. For example, Al Hashlamoun (2021) in a study of Arab students studying in Western institutions, highlights that these students prefer to speak in their mother tongue, and they find it difficult to use elearning tools and feel demotivated as they did not find the programme relevant to themselves and/or their sociocultural context. The participants in the current study have thus adopted and adapted a Culturally Relevant Pedagogy through providing their students with more equitably accessible educational resources with the aim to minimise technological apprehensions due to cultural and linguistic barriers. Hence, the purpose of this study is to highlight how adopting such a pedagogical approach can be instrumental in facilitating students' learning as they will, in all likelihood, be "enabled" to follow instructions and use educational technology in a more effective and efficient manner.

\section{The Study}

\subsection{Literature Review}

\subsubsection{Ethnomethodology, Acculturation, Cultural Relative Pedagogy}

In 1967 Garfinkel, the prominent American sociologist developed the theory of ethnomethodology which is principally based on phenomenology. Phenomenology is a school of philosophy concerned with the study of lived experiences as opposed to the actual phenomena and their properties in the real world. The concept of ethnomethodology is of distinct relevance to educational practices in different social contexts. This is because both the theory and the praxis of educational activity at all levels implicate situated linguistic and non-linguistic activity encompassing contextual, reactive and descriptive features (Keller, 2011; Meyer, 2019).

These unique qualities require a constant meaning-making and meaning-giving approach that helps translate the theoretical principles into relevant and practical activities. Therefore, it is important to understand the specific socio-cultural context in which the situated pedagogical activity takes place (Dunn, Sondel and Baggett, 2018). The nature of this activity is thus defined by the design of the lesson and the predictable as well as the unpredictable linguistic and non-linguistic behaviour of the participants (Wilson, 2019). In particular, the observation and description of both teachers and students' demeanor may lead to a unique understanding which helps develop the right ethnomethodological approach to pedagogy, one that allows for the specifics of the context, the social rules and expected norms (Scott, Hirn, and Cooper, 2017).

In such a scenario, the use of any type of methodological approach necessitates adaptation and acculturation. Lakey (2003) posits that "... the terms "assimilation," "cultural integration," "accommodation," "absorption," and "self-identification" are used, not necessarily equivalently, but to refer generally to the concept of "acculturation." (p.106). Similarly, Ng and Nagayama (2011) maintain that "Acculturation is a multidimensional process of how one 
culture adopts aspects of another culture's values and behaviors such as attitudes, language, and beliefs. It is generally defined as a change in cultural attitudes, values, and behaviors due to contact of one culture with another...". Berry (2005) also defines acculturation as "... the process of cultural and psychological change that takes place as a result of contact between cultural groups and their individual members." Sam (2015) argues that acculturation results in "affective", "behavioral" and "cognitive" changes in the individual.

The process of education is without a doubt one with its own acculturation features for both the teachers and the learners especially when they come from different backgrounds and are accustomed to specific cultures of and beliefs about education. For example, Cilesiz (2015) in a study of undergraduate university students' experiences with recorded lectures, highlights four stages of "ignorance", "disillusionment", "crisis" and "coping" that students undergo before completely being acculturated into using recorded lectures as a viable substitute for face-to-face lectures (p.478). Correspondingly, Choney, Berryhill-Paapke and Robbins (1995) recommend a five-level model of acculturation which shows how individuals move from their "traditional orientations", "transitional orientation", "bicultural orientation", "assimilated orientation" and finally a "marginal orientation". The traditional orientation signifies attachment to one's own cultural norms and traditions, while the transitional stage is characterised by becoming familiar with the new culture. The bicultural orientation shows how the individual is accepting both cultures as viable ways of doing things. The assimilated orientations are mostly inclined towards the new culture with some remnants and familiarity with the first culture. Finally, a marginal orientation reveals being uncomfortable with both cultures. The movement from one stage to another is not always linear, but each stage has its own characteristics and features. Today's universities not only comprise people from different linguistic and cultural backgrounds, but also constitute plural cultures of education due to the fact that professors and students come from diverse social and institutional cultures.

Doubtless, the culture of higher education in the twenty-first century is an amalgamation of diverse social cultures and traditions as well as a variety of cultures of education, i.e. norms of teaching and learning. In such a context, teachers bring their own teaching styles and students bring to the university their expectations of what a culture of higher education should constitute and represent. The researchers believe that this complex system of cultures within cultures reveals transitions from one stage to another at every level. New methodologies including innovative educational technologies are no exception. Thus, moving from one stage to another is gradual, gradational and not necessarily straightforward, filled with obstacles in terms of acceptance from both the students and teachers.

\subsubsection{Characteristics of Culturally Responsive/Relevant Pedagogy}

Ladson-Billings (1995) believes that a culturally responsive pedagogy is a dynamic approach, one that focuses on and fosters students' academic success, promotes their cultural competence and inculcates in them critical cognisance as regards the social ramifications of their environs. She believes it is only through effective conceptualization of notions of "self", "other" and "knowledge" that educators and researchers alike can develop a sound understanding of culturally relevant pedagogy and apply the principles in their teaching and/or research. (Ladson-Billings, 1995 and 2014).

Jabbar and Mirza (2019) believe a culturally responsive pedagogy in higher education is based on five major concepts of cultural consciousness, resources, moral responsibility, cultural bridging and curriculum. They believe an effective culture of higher education allows for capitalising on plurality of and interaction between cultures, strengthening moral and professional responsibility and responsiveness and enabling students to become successful through the use of resources and effective curricula. Similarly, Ladson-Billings (2014) argues that a culturally relevant or "sustaining" pedagogy is characterized by a flexible understanding of cultures and teaching methodologies that allow for equality and equitableness. Adopting such an approach in educational settings where teachers and students represent multiple ethnicities can in all likelihood be conducive to teachers becoming more reflective and aware of their role as educators to allow for differences (Samuels, 2018; Johnson, and Elliott, 2020). These studies indicate that an understanding of students' cultures, their competency levels and their learning styles, can help design teaching activities that are outcome-based and relevant to students' lives. The studies also show that through adopting a culturally responsive pedagogical approach, educators can develop more valid and meaningful assessments that help evaluate students' achievement in diverse ways. 
Gay (2002) posits that a culturally relevant pedagogy should embrace and promote knowledge of diverse cultures, include curricula that are culturally relevant, foster caring cultures and communities, facilitate communication between cultures and create cultural affinity in teaching. Adopting a culturally relevant pedagogy is seemingly a more cumbersome and complex process when teachers and students do not speak the same language, and come from different countries and socio-educational backgrounds with specific cultures of education.

A number of studies explore the effectiveness of a culturally relevant pedagogical approach in different sociocultural contexts. For example, Hamdan Alghamdi (2014) in a study of expatriate teachers' pedagogical practices in Saudi Arabia, discovered that adopting a culturally relevant pedagogy was rather challenging for these teachers. This was mostly because of teachers and students' different beliefs about what constitutes teaching and learning, which in turn made adjusting teaching unwieldy for the teachers. In another study of two expatriate teachers working in China who had distinctly different teaching approaches, Shi (2017) considers being straitjacketed by stereotypes a big impediment in having a culturally relevant pedagogical approach and highlights the importance of establishing a dialogue between local students and foreign teachers in order to become familiar with their perspectives on best practices in the local context and proceed accordingly.

\subsubsection{Acculturation of technology, "EdTech culturation"}

Education around the world has diverse origins. In the Gulf region, for example, education started with religious schools or madrasas with mostly mimicry and memorisation drills and exercises (Alhebsi, Pettaway and Waller, 2015). In the Americas, first nations people used education as a way to pass on skills such as knowledge of the land and knowledge of native traditions (Urban, Wagoner, and Gaither, 2019). English education has its roots in an interplay between church, apprenticeship, family and community (Cremin, 1970). Indian education, one of the oldest in the world, focused on verbal and religious education for boys and practical skills for women (Jayapalan, 2005)

Regardless of the origins, while informal education was widespread, much of the early days of formal education was only available to a few individuals. However, the recent trend is for education to be available on a mass scale in order to provide an outlet for upward mobility. Ramirez and Boli (1987) claimed that mass schooling originated in Europe in the eighteenth and nineteenth century and has branched out to other parts of the world ever since. Spring $(2008 ; 2015)$ argued that mass formal education is one of the main commonalities that all countries and cultures now share.

As a legacy of European education and because of the spread of American ideas throughout the world, many education systems mirror structures developed by and for these populations. For example, textbooks and other resources are often created by and for a population rooted in European cultures or a non-localized context (Ajibade and Elemi, 2012) Therefore, the content, imagery and context all reflect these origins. However, there is a need to create educational systems and resources that focus on reinforcing the needs of diverse populations (Quaye, Harper and Pendakur 2019).

Parallel to the emergence of this need, has been the importance of digital technologies as a central component to education and society at large. In order to support the needs of current and future learners, digital technologies have the potential to be a source for learner agency. However, in order to ensure that educational technology is integrated successfully in various contexts, there is a degree of EdTech culturation that needs to occur $(\mathrm{Wu}, 2017)$. Thus, professionals involved with creating educational technology resources should consider EdTech culturation that focuses on the following: (1) the way local community views learning activities; (2) the needs of localized communities within the larger world; (3) the involvement of individuals from the local culture in the design of materials; (4) an increase in learner autonomy (Dang, 2010). Clearly, the ultimate goal is to promote educational technology that forms a connection between the learner's identity and the materials, and for the digital technology tool to be both culturally and cognitively additive and not subtractive. In other words, individuals and local communities should be able to use technology as a means to explore their own learning needs and preferences based on their lived experiences in such a way that they could develop a good degree of educational autonomy. 
These challenges hold true for educational technologists in the United Arab Emirates and the Arab world in general. Multiple studies describe the use of educational technology in the United Arab Emirates, which include flipped learning, blended learning, student perceptions and iPad integration (Hani, 2014). However, more research needs to be conducted to explore the best ways to utilise technology in the local context. Such research will aim to increase agency for Emirati students based on their individual social, and local needs, and help determine why these strategies are successful in this context or otherwise.

Previous studies indicate that Emirati students prefer to learn collaboratively and value personal relationships (Rapanta, 2014). Culturally, they place great importance on their community, their family and their religion (Engin and McKeown, 2012). Therefore, including all or some of these elements when designing digital tools could conceivably make learners feel more connected and supported culturally. This idea was highlighted by Rogoff (2003) who argued that curriculum and lesson designers should focus on the needs of the individual learners in a community as well as the culture needs of the cultural community as a whole. Similarly, Sulecio de Alvarez and Dickson-Deane (2018) state: "This allows for mindful incorporation of new perspectives to enrich learning experiences, by stimulating the strengths of local cultural processes, instead of alienating the communal perspective" (p. 346 ).

The authors further argue that educational technology has the potential to be transformative. It can provide learners with tools to create their own meaning that are easily disseminated and adapted to future needs. (Sulecio de Alvarez and Dickson-Deane, 2018).

In line with the main principles of a culturally responsive pedagogy and the relevant findings in the studies reviewed herein, the authors seek to investigate and shed light on the following areas:

- How can an educational technology project successfully implement culturally appropriate technology?

- What are some of the pedagogical barriers to using educational technology in a local context?

- What are some of the cultural barriers to using educational technology in the UAE?

The study was conducted in the United Arab Emirates where the researchers and the participants are currently living and working.

\section{Methodology}

\subsection{Participants}

This research is a qualitative case study of three participants, two of whom are from the United States and one is from the United Kingdom. All participants teach undergraduate courses at a university in the United Arab Emirates. In addition to teaching at university, the participants also develop pedagogical applications and digital teaching and learning tools for use within a university context. The three participants are western-educated professors who have lived and worked in the United Arab Emirates for more than a decade. Their teaching experiences are varied and include teaching English as a Second Language, Education Studies and Mathematics to the undergraduate students who are almost all from the United Arab Emirates. Due to the increasing need in their professions to develop and use technology in teaching at university, the participants in the study have been involved in creating educational technology tools to support teaching and learning in the local context. Learners used these applications on their digital devices as ancillary pedagogical facilities. The participants also created online classes open to the public to provide support for learners who are mostly Emiraties and needed to improve various academic skills including their knowledge of English. The participants also designed online classes for the professional development of preK-12 teachers using bilingual features as well as local imagery and concepts to make it easier for them to master teaching of the foundations of English Grammar. The selection of the participants in this study has been in line with "purposive sampling", as the three participants share an interest in Culturally Relevant Pedagogy (CRP).

\subsection{Research Instrument}

In order to collect data for the study, structured interviews were administered online with the use of Google Docs. Due to the current pandemic, for the purpose of minimising the possible health risks, the online platform was used 
for data collection. In order to seek the insights and opinions of the participants in the study, they were asked to comment on the cultural relevance, cultural appropriateness and cultural barriers of the projects they had developed. They were also asked to reflect on how their projects have been able to support learning and reflect on their noticeable successes as well as inadequacies. The interview questions were informed by and developed based on the existing literature in the field, the researchers' personal observations of their students' difficulties in their classes, and their teaching strategies to help them master the relevant knowledge and skills. The use of Google Docs as a way of recording responses to interview questions proved to be practical and effective, as the researchers were able to ask follow-up questions based on the information already furnished by the participants, which enriched the data collected for the study. (The list of questions appears in Appendix I).

\subsection{Research Design}

Considering the nature of the study conducted, the researchers opted to adopt a case study approach to investigate the research problem. The choice of a case study was deemed advisable, as the participants teach different subjects in different departments at university, and this can enrich the study as each participant will bring discipline-specific teaching experiences and insights into the current research. Likewise, the participants' unique experiences in developing different educational technology tools can help see the problem of a Culturally Relevant Pedagogy from different angles, i.e., based on their own experiences of using these tools and how these tools can address the needs of their students. The fact that all participants teach in the same context can also highlight the similarities in terms of the problems they face in either developing or teaching their students in the same context.

\subsection{Data Analysis}

As stated earlier, the qualitative data collected in this study is in the form of case studies of three professors who are all educators and experts in developing educational applications as well as digital teaching and learning tools. The data was collected over a period of one month. Each participant's responses on Google Docs were analysed using the qualitative analysis method, and the salient themes were selected for presentation in this paper. Each researcher individually coded the data based on what they considered a "salient" theme. Salience of the themes was determined through considering the significance attached to a theme by any of the participants. In order to maintain the trustworthiness of the themes, (Lincoln and Guba, 1985) the emergent themes were collated, and the researchers re-visited the data over a period of three months and agreed on what constituted the main themes in the three case studies.

In the following sections, each case study will be presented using fictitious names to maintain confidentiality of the participants. Throughout the study, and in the revision process, they were sent every version of the draft. They gave their written consents to use the given names and the data used for the presentation in the study.

\section{Findings}

\subsection{Case Study One: Jacob, A Mathematics Education Researcher and Digital Application Developer}

Jacob has extensive experience of teaching mathematics in different countries and various sociocultural settings, and has been involved in developing educational tools for his students who come from different cultural and linguistic backgrounds. In the following section, the main themes in Jacob's responses to interview questions will be explored.

\subsubsection{Linguistic barriers and student learning}

Jacob believes that there are many western apps that help students strengthen their mathematics skills through games and manipulations of the relevant mathematical tasks and activities. However, he thinks that most of these apps do not consider students' culture and/or mother tongue.

When asked to reflect on one of his educational technology research projects, Jacob distinctly highlights the importance of these factors in developing his project:

These two factors were taken into consideration when a research project was designed to create an IOS math app to allow grade six Emirati students an opportunity to explore mathematics, along with using Bayesian Networks to examine the educational implications. The learning app was developed using 
ethnomathematics modules, based on the Emirati culture. Students were required to navigate through several modules to explore various mathematical concepts from algebra and geometry. Some aspects of the app were translated to Arabic....

4.1.2 The importance of cultural relevance in developing educational technology:

When Jacob was asked to comment on how he made this project culturally relevant, he mentioned:

Our project is considered culturally relevant, since we aim to connect the students' culture to the curriculum. In other words, we allow students to have a meaningful experience with mathematics. For example, in our pilot study, each prospective Emirati early childhood teacher was required to create one ethnomathematics learning activity based on the Emirati culture that could be displayed on our mobile device. One prospective early childhood teacher created an activity using a Talli (حرفة التلي) - a type of embroidery that is used on Emirati women's clothes. To make a Talli a Cajoja (كجوجة machine is used. The student explained that in the beginning, she was highly interested in exploring mathematics and the Emirati culture; and was unable to think of an idea. She further described the assignment to her grandmother; and her grandmother gave a wonderful example - Talli (حرفة التلي). The student was aware that her grandmother designed and created Talli but never knew the extent she went through to develop the Talli. In the end, she and her grandmother designed and created Talli (حرفة التلي) together.

In response to the question about ways of successfully developing culturally appropriate educational technology, Jacob further comments:

For example, one module for our second Math App will explore the use of a Gargoor (Arabic القرقور). A Gargoor is a traditional Emirati dome-shaped wire-netting cage that is used in fishing. A fish enters the Gargoor through the funnel entrance and is unable to leave the cage. In 2019, the UAE government banned the use of the Gargoor due to endangered fish entering the cages and abandoned cages. The module requires students to create an alternative to the Gargoor that could be used by an Emirati fisherman. The module supports innovative ideas such as the material used to create the Gargoor; otherwise, the Gargoor floats. Again, we want students to use their creative imagination to design an alternative structure to the Gargoor.

\subsubsection{Institutional and gender-based perceptions of educational technology}

When asked about barriers he faced in developing apps, Jacob responded:

The only pedagogical barrier we have experienced is the idea that a mobile device is typically considered a tool for entertainment, rather than a learning tool. This perception is mostly held by teachers and/or administrators.

We have experienced such cultural barriers as cultural perceptions and gender concerns... Our research findings convey a dramatic difference for girls and boys learning mathematics using a mobile device (Johnson and Cory, 2020). Based on our findings, girls prefer not to use a mobile device to learn mathematics. However, boys do prefer to use a mobile device to learn mathematics.

When Jacob was asked about the specific tools, ideas, processes that have been successful for students in the UAE, he observed:

For instance, the Emirati sixth-graders in our study, preferred to use a mobile device to explore ethnomathematics, have a deep connection to the Emirati cultural artifacts, and favored to learn mathematics using ethnomathematics based on the Emirati culture. The Emirati sixth-graders showed appreciation for the artifacts used (Henna, Prayer beads, and Bamboo Baskets) in our first Math App. For example, the students do not create Bamboo Baskets from gathering the materials from a Bambusoideae tree; however, the students were able to create a Bamboo Basket using the features of a mobile device.

Generally, Jacob believes educational technology can support student learning in the UAE, and asserts: 
We believe the integration of STEM and/or STEAM with ethnomathematics could be common practice for classroom teachers. The $21^{\text {st }}$ century student is synonymous with technology. We also believe that 3D (3Dimensional technology) visuals with ethnomathematics could greatly enhance Emirati students' experience with mathematics... Many ethnomathematics experiences may not be accessible for students. However, using 3D technology would bring ethnomathematics to the classroom.

Jacob's observations indicate that while there might be some barriers in implementing culturally appropriate educational technology in creating digital tools in contexts that are different from that of the educator's, adopting and adapting concepts and technologies that can facilitate student learning is a fruitful enterprise. He believes that through augmentation techniques, we can acclimatise and localise the educational applications to achieve success in teaching and assessing knowledge and improving learning at the same time. In general, Jacob's observations attest to the fact that EdTech culturation is a valid methodological approach as it embraces the cultural vicissitudes of the local context, allows for students' specific linguistic and non-linguistic needs and provides a solid foundation for them to engage in learning inside and outside the classroom.

Jacob's responses are in line with other researchers' findings with respect to the use of technology in the classroom. For example, Nye (2015) argues it is important to allow for language and cultural localisation when using technology in educational contexts. Similarly, Gogus et al. (2012) and Nistor, Göguüş. and Lerche .(2013) show that students' culture plays a significant role in their acceptance of the educational technology used in the classroom and can have a significant impact on students' success.

\subsection{Case Study Two: Jackie, A Professor in Early Childhood Education and a Specialist in Literacy and Educational Technology}

Jackie has 25 years of experience of working with Second Language Learners (SLL) and has worked in North America and the Middle East. Her rich background of developing and using educational technology has enabled her to observe her students' struggles and successes in the use of technology. Below are the salient themes that emerged in her responses to interview questions:

\subsubsection{The importance of using simple language in educational applications}

When asked about her educational technology projects, Jackie commented:

I have been involved in several projects aimed at developing online materials for Gulf Arabs. I assembled a team of individuals who have many years of experience working in the region. Many have educational technology backgrounds, $K-12$ backgrounds, bilingual and SLL teaching experience... The team helped develop online materials that embed local context such as images, history, concepts and experiences. Audio was made with the local population in mind. English was slowed down to teacher talk levels or content materials were translated into Arabic...

When asked if her project was culturally relevant, she explained:

We used language that the learner could understand. We used the local context to include images, ideas and belief systems all the while keeping true to the globalized nature of the UAE.

\subsubsection{The importance of using culturally relevant educational technology in the classroom}

Jackie believes in the successful implementation of culturally relevant educational technology, she contends: It is important to make sure that the design connects with the students and is not offensive, and that students are not hindered by difficult language. Using local resources when available is a very significant criterion to allow for when developing educational technologies.

When asked about possible barriers in implementing a culturally relevant pedagogy in the local context, Jackie mentioned:

It is of great importance to make sure that students know how to use the technology, so that the teacher can use the pedagogy correctly in the first place. It can't be too cumbersome. Also, students are often used to rote learning and PowerPoint delivered lessons. ... That shouldn't stop someone from using 
constructivist and situated pedagogy but just be aware that it takes some time for students to become acclimated to learning this way.

\subsubsection{The significance of cultural and competency-based barriers}

When Jackie was asked about the cultural barriers in using culturally appropriate pedagogy, she mentions that she finds students' lack of interest in taking the initiative in speaking or revealing their identity as the main cultural barrier:

Not showing faces or speaking for fear of someone taking pictures or recording. The same is true for using open forums.

Jackie believes that in general, tools and educational approaches should have certain features to be successful in the local context. She reflects:

In general, those applications and digital tools are successful that dovetail well with the students' level of knowledge, skills and abilities. The ones you can use in a variety of contexts such as videos, collaborative tools like kahoot, quizlet, etc. The applications should first and foremost have a variety of features that can accommodate a variety of students with different levels of knowledge and interest. It is important to employ the knowledge of an expert in the local culture making sure that what is being used is accessible and non-offensive in nature.

Jackie comments on how educational technology can support student learning and she asserts:

I think the best way to support student's learning is using a flipped or blended format. Even during COVID, students still needed a lot of teacher support. Technology should never be viewed as core.

Jackie argues that one way of determining the success of an educational technology project would be how students evaluate it in terms of interactivity, simplicity of use, student-friendliness, but more importantly how students can complete the relevant tasks and achieve the course learning outcomes.

Jackie's responses are particularly interesting because she focuses on the competency level of students and the fact that any educational technology tool should correspond with this competency level. This is an important pedagogical consideration as without knowing the students, their needs and their current knowledge and skill in a given area, the relevant applications cannot be developed or can be ineffective. Her emphasis on interactivity, accessibility and adaptability also speak of the important features of culturally relevant pedagogy. Her overall inclination towards technology that makes sense to the teacher and to the student, brings to the fore a muchneglected aspect of pedagogy and as such she also highlights the importance of EdTech culturation as an effective teaching approach that embodies students' current knowledge and skills level as well as their inhibitions in using technology.

Jackie's responses are in line with the research findings of Dodson, Sterling and Bennett (2013) who show that lack of adeptness in the use of language and technology presented serious problems for the female participants in their study. Ullah, Ali and Hussain (2021) also emphasise that it is important for teachers when using educational technology to use simple, jargon-free and thus accessible language so that students can follow instructions and complete relevant tasks. Likewise, Al-Maroof, et al. (2020) contend that students' motivation, how they perceive the use and usefulness of educational technology play a significant role in their learning behaviour and achieving the learning outcomes.

\subsection{Case Study Three: Miles, A Language-Teaching and Educational Technology Specialist}

Miles has 24 years of ELT teaching experience in Asia and the Middle East. Teaching general and academic English to all levels and ages ranging from 3 to 83 years old. Miles developed an application for developing students' academic vocabulary. This is how he describes his project:

AVA (Academic Vocabulary App) is a self-access, mobile vocabulary learning app that aims to help Arab learners develop their receptive knowledge and productive use of 600 general academic word families and their most frequent and useful collocations.... 
Below are the salient themes that emerged from Miles's responses to interview questions.

4.3.1 The importance of using culturally appropriate content and imagery in educational applications:

When Miles was asked if his project was culturally relevant, he stated:

...the English spellings of some Arabic words were included in the content (e.g. kandora, the United Arab Emirates). We also tried to use images that reflected the regional culture and avoided inappropriate images of alcohol or women showing shoulders.

When asked about ways of developing culturally relevant educational technology in the UAE, Miles observed: Obviously, the content can be made culturally appropriate just as any other materials. In terms of the actual technology, Emiratis seem to have taken to the use of mobile devices very quickly - one of the highest mobile penetration rates in the world 228\% in 2017,(Arabian Business Industries, 2017)...My only suggestion is that students often lack device self-regulation for learning purposes... Maybe shorter and fun activities that students can complete quickly for their dopamine hits would also help.

\subsubsection{Over-dependence on and overuse of technology as an entertainment tool by students}

Miles believes there are some pedagogical barriers in using digital tools in education: Mobile apps and smartphones are often seen more as communication and entertainment devices, rather than serious learning devices. Students are also more easily distracted by social media and notifications on the phones and some suffer from nomophobia and digital addiction which impedes learning through ed tech.

He also mentions that there are some cultural barriers in the use of educational technology in the local context: There are few cultural barriers in using ed tech. Technology is very embedded in students' daily lives, so there are no barriers in terms of technology. Perhaps, using online groups/forums across organisations and countries is more difficult because UAE females want to maintain privacy more, so won't show their faces and even use their voices unless they know the other people.

Miles comments on the tools and processes that have been successful in the UAE, and that they should enjoy certain features:

Seamless mobile learning that takes into account students' learning ecologies and links in-class with outof-class learning can be successful. The teacher needs to show students the tools, sell the benefits and the reasons for using them and use them in class, before students.... Integration is key.

4.3.3 The importance of adaptiveness of technological applications to students' knowledge and skills:

When asked about how educational technology can support student learning, Miles states:

I think if it's clearly linked to students' current level and fully adaptive to what they know and don't know, ed tech can be very effective for independent learning. Students need spaced repetition as well to aid longterm retention, so built-in reviewing and recycling with daily reminders can reduce the burden on students to remember to review. At the same time, online learning platforms should offer a range of communication tools that are easily accessible for students to contact each other and the instructor. Also, students need proper training in order to make the most of the technology. Yes, university students know how to navigate social technology, but they often don't know how to make the best use of technology for learning purposes and academic study.

Miles believes that student feedback in a survey, student ad hoc comments in class can be very informative as regards the success of an educational technology project or digital tool.

Miles has a very unique approach to the use of educational technology which is characterised by students' understanding of the ways of using digital tools inside and outside the classroom in a way that they become an integral part of the students' lives. He highlights the importance of training in achieving this goal and believes feedback on students' work can help open a dialogue between the student(s) and the teacher, and as such, the use of technology can be an effective pedagogical tool. According to Miles, this can be conducive to developing 
students' knowledge and more importantly the locus of control, i.e. they will own their own learning and they will learn to self-regulate more successfully. Mile's views also indicate that EdTech culturation as a methodological approach should be planned and implemented systematically in order to meet the students' educational needs. His observations reveal that through establishing a feedback cycle, the professor and the students engage in meaningful communication that can help iron out any inconsistencies or issues that get in the way of learning through the use of technology.

Miles' commentary highlight the importance of students' expectations and habits of technology use as highlighted by Aagaard (2015) findings which indicate that stuts because of their daily habits of using technology, students are often distracted when using educational technology in the classroom. Similarly, Seemiller (2017) argues that it is important to devise interventional practices that help students regulate their behaviour in terms of technology use in the classroom. Miles' observations as regards the importance of feedback on students' work are emphasised by Yengin (2017) who argues that students' learning behaviour can and should initiate appropriate feedback from the instructor and creates more effective communication between them.

\subsection{EdTech culturation: Towards establishing a practical model}

In light of the findings of the study, the researchers would like to propose the following model which encompasses the central themes as discussed earlier.

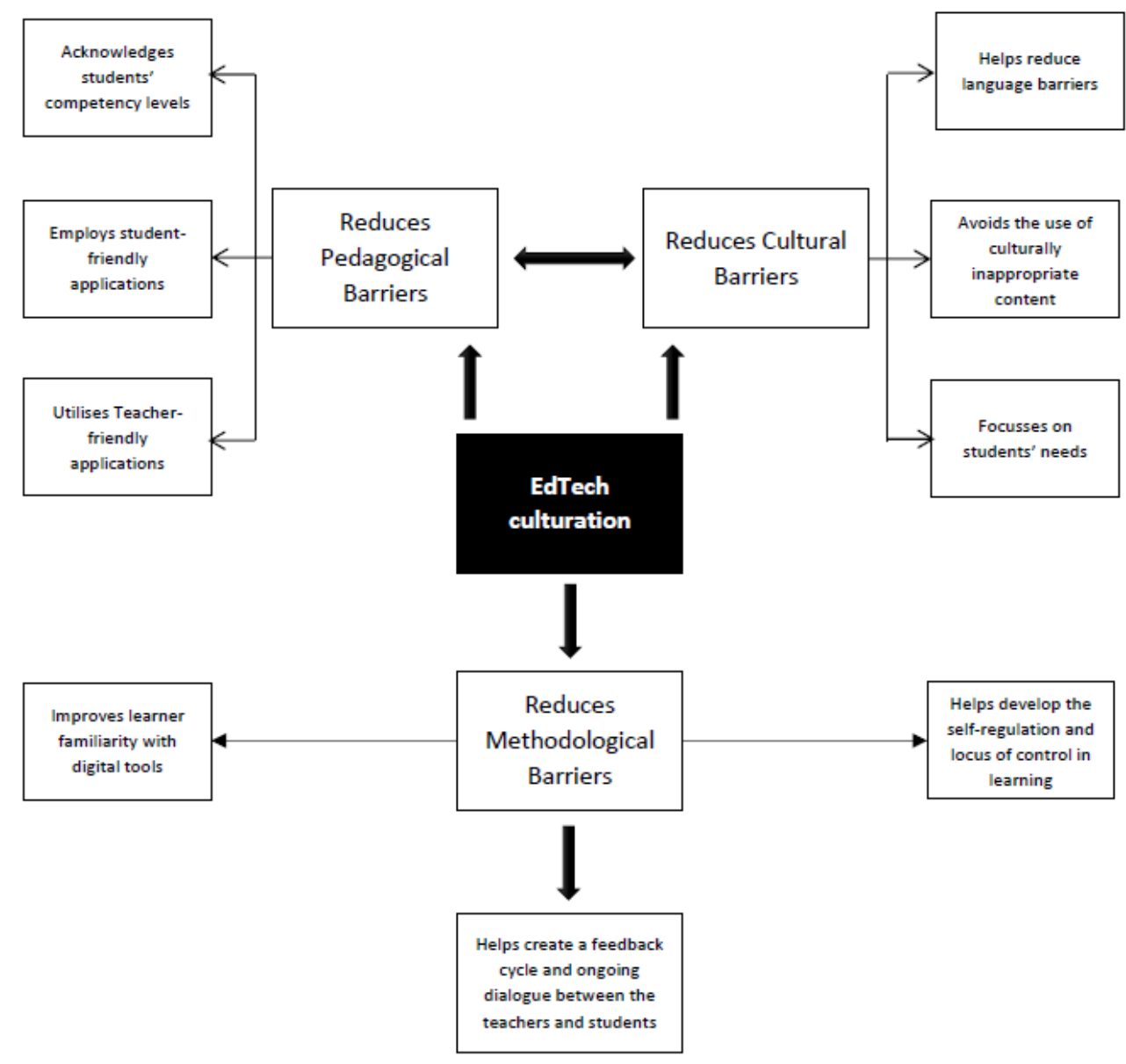

Figure 1: EdTech culturation Model based on the findings of the three case studies 
As the model reveals, in general, reducing cultural, pedagogical and methodological barriers can help develop a Culturally Relevant Pedagogy (CRP) which focusses on the use of educational technology that dovetails well with the needs of the students in a local context. Such a pedagogical approach, doubtless, is relevant and of practical significance to online education, e-learning, and technology-rich educational methodologies that are mostly innovative and often imported into contexts such as the one where this study was conducted. Hence, it can be argued that EdTech culturation in today's educational scenery is a practical approach which is appropriate and becoming of educational settings that comprise students who come from either heterogenous or homogenous backgrounds. This is because in today's world of education, the concept of one-size-fits all especially with respect to technology use in education is anachronous and ineffective. Becoming familiar with the local context, the language(s) spoken by the locals, and their specific needs in developing educational technology applications should require proper planning, research based on students and teachers' surveys and implementation. This methodological approach helps students better achieve their academic goals through facilitating their engagement in the process of learning inside and outside the classroom and as such is conducive to the consistency in their learning. The participants in the study point up the fact that it is only through acclimatising educational technology tools to the local context that we can further students' learning. EdTech culturation is thus, both a process and a product: it is a process as it involves constant meaning-making and meaning-giving to the students' learning experiences. It is also a product as it is created, used and modified in accordance with the changing needs of the learners. Adopting such an approach, the researchers believe, should be the new norm in today's dynamic educational scenery, one that involves constant change and readiness for change, and as such warrants being receptive, adaptive and innovative in one's use of technology in education. This way, perhaps, we will be able to aid our students succeed in achieving their learning objectives and will help them keep up with our changing times in a better prepared and more confident manner.

\section{Conclusion}

This study reported on the views of three professors, who are also developers of educational technology tools, on how "EdTech culturation" as an approach which embraces a culturally relevant pedagogy can be an effective methodological approach. The term "EdTech culturation" was introduced by the researchers as a portmanteau word combining technology, acculturation and education meaning that when the use of technology is culturally relevant and appropriate for the students in a given context, teaching and learning will be more effective. The three participants in the study all observed that educational technology use can be meaningful to both the educators and the students, when it helps establish a dialogue between both parties. Such a dialogue can only be created, if the cultural prescriptions and proscription are taken into account when developing educational technology tools. Based on the participants' observations, some of the main features that should be considered are the linguistic features of the applications, and the accessibility of languages to students, the appropriateness of imagery and concepts presented, and the current competency level of students in terms of a given subject area.

While these factors can be of significance in most educational settings, they are especially paramount in contexts where technology is used to facilitate the process of teaching and learning, e-learning and online education as we have experienced in the current pandemic. It should be noted that many educational technologies are developed in Western countries and are imported into local contexts. Therefore, these technologies may be cumbersome to use by the local students due to the fact that they may not be user-friendly technology-wise and culturally appropriate and may pose linguistic barriers. Such barriers disrupt the process of teaching and learning and can impede students from achieving the envisaged course learning outcomes. Adopting an Ed-Tech Culturation Approach will furnish the educational policy makers and educators to make more informed decisions about the design and implementation of courses that incorporate educational technology. Other researchers such as Selinger (2004) show that local cultures have a direct effect on teachers and students' belief of what should constitute the process of learning and teaching and what are the so-called acceptable norms. McLoughlin (2006) also postulates that in online education, it is important to allow for cultural and pedagogical factors such as linguistic and cultural differences as well as different learning and thinking styles, as educational settings are as diverse as the cultures they are housed in. Gogus et al. (2012) have adopted a similar position and have argued that cross-cultural differences play a significant role in accepting the use of technology. 


\section{Implications}

The current research can have several major implications for pedagogy and research. The EdTech Culturation Model, pedagogically, highlights the importance of knowing the linguistic and educational needs of the students, the teaching context, its cultural norms, prescriptions and proscriptions. Such knowledge, when delivering lessons using educational technology, or in online classes and/or on e-learning platforms can help establish a better connection with and understanding of the students and their culture(s) and can thus create a better teacherstudent dialogue. It is believed that this dialogue which is essentially pedagogical paves the way for the mastery of course-related knowledge and skills. Another pedagogical implication of the current study is the role of acceptance and responsiveness to different linguistic and competency-based levels. The EdTech Culturation Model is characterised by a meaning-making and meaning-giving process in which the teacher becomes aware of and is sensitive to the needs of the students and provides the requisite assistance with language and educational technology accordingly. The study also has implications that can be of great significance for future research. While most research focusses on highlighting the importance of methodological factors influencing teaching and/or learning, more research is needed to show how technology-mediated education as a unique model can have its own unique affordances. More research is needed to show how students and teachers may be better "enabled" to utilise these affordances through adopting an EdTech Culturation approach. Another important implication of the present research is to study how teacher orientation programmes based on a good understanding of the local culture, can be instrumental in developing the requisite skills for teachers who are new to teaching in an educational context and how to integrate educational technology effectively into their lessons. This information can provide more insight into more effective teaching and learning in local contexts.

\section{References}

Aagaard, J., 2015, Drawn to distraction: A qualitative study of off-task use of educational technology, Computers and Education, 87, pp. 90-97. https://doi.org/10.1016/j.compedu.2015.03.010

Ajibade, B. and Elemi, N. E., 2012. The importance of visual illustrations in recommended primary and secondary school textbooks in Calabar. Journal of Educational and Social Research, 2(1), pp. 161-161. Doi: 10.5901/jesr.2012.02.01.161

Al Hashlamoun, N., 2021. Cultural challenges eLearners from the GCC countries face when enrolled in Western educational institutions: A thematic literature review. Education and Information Technologies, 26(2), pp.1409-1422. https://doi.org/10.1007/s10639-020-10313-1

Alhebsi, A., Pettaway, L, and Waller, L, 2015. A history of education in the United Arab Emirates and Trucial Shiekdoms. The Global eLearning Journal, 4(1), pp. 1-6.

Al-Maroof, R.S., Salloum, S.A., AlHamadand, A.Q.M. and Shaalan, K., 2020. Understanding an extension Technology Acceptance Model of Google Translation: A multi-cultural study in United Arab Emirates. International Journal of Interactive Mobile Technologies, 14(3), pp. 157-178. DOI:10.3991/ijim.v14i03.11110

Arabian Business, 2017. UAE's mobile phone penetration rises 228\%. Available at: https://www.arabianbusiness.com/uae-smobile-phone-penetration-rises-228--676115.html. [Accessed January 31, 2021]

Aysan-Sahintas, Z., 2019. It's in my blood: An expatriate English language teacher's pedagogical practices and identity. IManager's Journal on English Language Teaching, 9(1), pp. 1-13. http://dx.doi.org/10.26634/jelt.9.1.15175

Berry, J. W., 2005. Acculturation. In W. Friedlmeier, P. Chakkarath, and B. Schwarz, Eds., 2005. Culture and human development: The importance of cross-cultural research for the social sciences. Psychology Press/Erlbaum (UK): Taylor \& Francis. pp. 291-302

Bond, M., Buntins, K., Bedenlier, S., Zawacki-Richter, O. and Kerres, M., 2020. Mapping research in student engagement and educational technology in higher education: A systematic evidence map. International Journal of Educational Technology in Higher Education, 17(1), pp 2. https://doi.org/10.1186/s41239-019-0176-8

Choney, S. K., Berryhill-Paapke, E., and Robbins, R. R., 1995. The acculturation of American Indians: Developing frameworks for research and practice. In: J. G. Ponterotto, J. M. Casas, L. A. Suzuki, and C. M. Alexander (Eds.), Handbook of multicultural counselling. Thousand Oaks, CA: Sage Publications, Inc. pp. 73-92. Available at: https://psycnet.apa.org/record/199598648-005 [Accessed August 8 2021]

Cilesiz, S., 2015. Undergraduate students' experiences with recorded lectures: Towards a theory of acculturation. Higher Education, 69(3), pp. 471-493. https://doi.org/10.1007/s10734-014-9786-1

Cremin, L. A., 1970. American education: The colonial experience, 1607-1783 (Vol. 1). New York, London: Harper \& Row

Dang, T. T., 2010. Learner Autonomy in EFL Studies in Vietnam: A Discussion from Sociocultural Perspective. English Language Teaching, 3(2), pp 3-9. DOI:10.5539/elt.v3n2p3

Dodson, L.L., Sterling, S.R. and Bennett, J.K., 2013, December. Minding the gaps: Cultural, technical and gender-based barriers to mobile use in oral-language Berber communities in Morocco. In Proceedings of the Sixth International Conference on 
Information and Communication Technologies and Development. Cape Town, South Africa. 7-10 December 2013. New York, Association for Computing Machinery. DOI:10.1145/2516604.2516626

Dunn, A., Sondel, B., and Baggett, H., 2018. "I Don't want to come off as pushing an agenda": How contexts shaped teachers' pedagogy in the days after the 2016 U.S. presidential election. American Educational Research Journal, 56(2), pp. $444-476$. https://doi:10.3102/0002831218794892

Engin, M. and McKeown, K., 2012. Cultural influences on motivational issues in students and their goals for studying at university. Learning and Teaching in Higher Education: Gulf Perspectives, 9(1). Available at: <http://Ithe.zu.ac.ae> [Accessed 22 February 2021]

Garfinkel, H., 1967. Studies in ethnomethodology. Englewood Cliffs, N.J: Prentice-Hall.

Gay, G., 2002. Preparing for culturally responsive teaching. Journal of Teacher Education, 53(2), pp. 106-116. https://doi.org/10.1177/0022487102053002003

Gogus, A., Nistor, N., Riley, R.W. and Lerche, T., 2012. Educational technology acceptance across cultures: A validation of the Unified Theory of Acceptance and Use of Technology in the context of Turkish national culture. Turkish Online Journal of Educational Technology-TOJET, 11(4), pp.394-408.

Hamdan Alghamdi, A., 2014. The road to culturally relevant pedagogy: Expatriate teachers' pedagogical practices in the cultural context of Saudi Arabian higher education. McGill Journal of Education/Revue des Sciences de l'Éducation de McGill, 49(1), pp. 201-226. https://doi.org/10.7202/1025778ar

Hani, N. A. B., 2014. Benefits and barriers of computer assisted language learning and teaching in the Arab world: Jordan as a model. Theory and Practice in Language Studies, 4(8), pp. 1609. DOI:10.4304/tpls.4.8.1609-1615

Jabbar, A. and Mirza, M., 2019. Managing diversity: academic's perspective on culture and teaching, Race Ethnicity and Education, 22:5, pp.569-588, DOI: 10.1080/13613324.2017.1395325

Jayapalan, N., 2005. History of education in India. New Delhi: Atlantic Publishers \& Distribution.

Johnson, A., and Elliott, S., 2020. Culturally relevant pedagogy: A model to guide cultural transformation in STEM epartments. Journal of Microbiology \& Biology Education, 21(1), 21.1.35. https://doi.org/10.1128/imbe.v21i1.2097

Keller, R., 2011. The Sociology of Knowledge Approach to Discourse (SKAD). Human Studies, 34(1), pp. 43-65. https://doi.org/10.1007/s10746-011-9175-z

Kennedy, M., and Dunn, T. J., 2018. Improving the use of technology enhanced learning environments in higher education in the UK: A qualitative visualization of students' views. Contemporary Educational Technology, 9(1), pp. 76-89. https://doi.org/10.30935/cedtech/6212

Ladson-Billings, G., 2014. Culturally relevant pedagogy 2.0: aka the remix. Harvard Educational Review, 84(1), pp.74-84. https://doi.org/10.17763/haer.84.1.p2ri131485484751

Ladson-Billings, G., 1995. Toward a theory of culturally relevant pedagogy. American Educational Research Journal, 32(3), pp. 465-491. https://doi.org/10.3102/00028312032003465

Lakey, P. N., 2003. Acculturation: A review of the literature. Intercultural Communication Studies, 12(2), pp. 103-118.

Lincoln, Y.S. and Guba, E.G., 1985. Naturalistic inquiry. New Delhi: Sage Publications.

Mahani, S., 2018. A self-study of culturally relevant pedagogy in a Higher Education Institution in the United Arab Emirates. In: E Lyle (ed) 2018. Fostering a relational pedagogy. Leiden, The Netherlands: Brill | Sense. pp.82-92. https://doi.org/10.1163/9789004388864 008

McLoughlin, C., 2006. Adapting e-learning across cultural boundaries: A framework for quality learning, pedagogy, and interaction. I:n A Edmundson, (ed), 2006. Globalized e-learning cultural challenges. London: Information Science Publishing. pp. 223-238

Meyer, C., 2019. Ethnomethodology's culture. Human Studies, 42(2), pp. 281-303. http://dx.doi.org/10.1007/s10746-019$\underline{09515-5}$

Ng, J., and Nagayama, H., 2011. Cultural Influences on Adolescent Development. In: B. Brown and M. Prinstein, (eds), 2011. Encyclopedia of adolescence. US: Academic Press.pp. 44-31

Nistor, N., Göğüş, A. and Lerche, T., 2013. Educational technology acceptance across national and professional cultures: a European study. Educational Technology Research and Development, 61(4), pp.733-749

Nye, B.D., 2015. Intelligent tutoring systems by and for the developing world: A review of trends and approaches for educational technology in a global context. International Journal of Artificial Intelligence in Education, 25(2), pp.177-203.

O'Donnell, E. and Sharp, M., 2012. Students' views of e-learning: the impact of technologies on learning in Higher Education in Ireland. In: K. Moyle and G Wijngaards, (eds) 2012. Student reactions to learning with technologies: perceptions and outcomes. Hershey, PA: IGI Global. pp. 204-226. http://doi:10.4018/978-1-61350-177-1.ch010

Edarabia. (n.d.) Population of the UAE, 2020. Edarabia. Available at https://www.edarabia.com/population-uae/ [Accessed 08 September 2020]

Qs Top Universities., 2020. Qs Top Universities. Available at https://www.topuniversities.com/universities/zayeduniversity/undergrad[Accessed 08 September 2020]

Quaye, S. J., Harper, S. R., and Pendakur, S. L. , 2019. Student engagement in higher education: Theoretical perspectives and practical approaches for diverse populations. New York: Routledge. 
Ramirez, F., and Boli, J., 1987. The political construction of mass schooling: European origins and worldwide institutionalization. Sociology of Education, 60(1) pp 2-17. https://doi.org/10.2307/2112615

Rapanta, C., 2014. "Insha' Allah I' II do my homework": adapting to Arab undergraduates at an English-speaking University in Dubai. Learning and Teaching in Higher Education: Gulf Perspectives, 11(2), pp 60-67. https://doi.org/10.18538/Ithe.v11.n2.177

Rogoff, B., 2003. The cultural nature of human development. New York: Oxford University Press.

Sam, D. L., 2015. Acculturation. In@ N. J. Smelser and P. Baltes, (eds). 2015, International encyclopedia of the social \& behavioral sciences. Oxford: Elsevier, pp. 68-74.

Samuels, A. J., 2018. Exploring Culturally Responsive Pedagogy: teachers' perspectives on fostering equitable and inclusive classrooms. SRATE Journal, 27(1), pp. 22-30.

Scott, T., Hirn, R., and Cooper, J., 2017. Teacher and student behaviors: Keys to success in classroom instruction. Lanham: Rowman \& Littlefield Publishers.

Seemiller, C., 2017. Curbing digital distractions in the classroom. Contemporary Educational Technology, 8(3), pp.214-231.

Selinger*, M., 2004. Cultural and pedagogical implications of a global e-learning programme. Cambridge Journal of Education, 34(2), pp.223-239. https://doi.org/10.1080/03057640410001700589

Shi, L., 2017. Two expatriate English instructors in China: Their experiences, and perspectives of local students and teachers. Canadian Modern Language Review, 73(1), pp. 1-23. https://doi.org/10.3138/cmlr.3086

Spring, J. 2008. Research on globalization and education. Review of Educational Research, 78(2), pp. 330-363. https://doi.org/10.3102/0034654308317846

Spring, J., 2015. Globalization of education: An introduction. New York: Routledge.

Sulecio de Alvarez, M., and Dickson-Deane, C., 2018. Avoiding educational technology pitfalls for inclusion and equity. TechTrends, 62, pp. 345-353. https://doi.org/10.1007/s11528-018-0270-0

UAE Ministry of Education: Quality education. 20 December, 2020. UAE Ministry of Education. Available at: $<$ https://u.ae/en/about-the-uae/leaving-no-one-behind/4qualityeducation> [Accessed 19 January 2021]

Ullah, Z., Ali, S. and Hussain, S., 2021. Linguistic barriers in online teaching at undergraduate level in the University of Malakand Pakistan. SJESR, 4(1), pp.158-163. https://doi.org/10.36902/sjesr-vol4-iss1-2021(158-163)

Urban, W., Wagoner, J., and Gaither, M., 2019. American education: A history. New York: Routledge.

Wilson, G., 2019. Ten quick tips for creating an effective lesson. PLoS Computational Biology, 15(4), pp. e1006915-12. https://doi.org/10.1371/journal.pcbi.1006915

$\mathrm{Wu}, \mathrm{Y}$. L., 2017. The use of technology during academic acculturation: case studies of Chinese-speaking international doctoral students (Doctoral dissertation, The Ohio State University).

Yengin, I., 2017. Importance of feedback in teaching, communication and information systems for learning. Komunikacija $i$ kultura online, 1(1), pp.309-317.

\section{Appendix I}

The questions that the participants were asked to answer to on Google Docs:

1. Briefly describe your professional/ academic background.

2. Briefly describe your research interests.

3. Describe your project.

4. How could your project be considered culturally relevant?

5. Based on your experience, provide your thoughts and reflections on the following:

1. How can an educational technology project successfully implement culturally appropriate technology in the UAE

2. What are some of the pedagogical barriers to using educational technology in the context of the UAE?

3. What are some of the cultural barriers to using educational technology in the UAE?

4. What are the specific tools, ideas, processes that have been successful for students in the UAE?

5. How can educational technology potentially support student learning in the UAE?

6. How did you determine success? 